\title{
THE EFFICIENCY OF UNIVERSITIES IN ACHIEVING SUSTAINABLE DEVELOPMENT GOALS
}

\author{
Lena Malešević Perović ${ }^{1 *}$ and Maja Mihaljević Kosor ${ }^{2}$ \\ ${ }^{12)}$ University of Split, Faculty of Economics, Business and Tourism, Split, Croatia \\ CERGE-EI Teaching Fellow
}

\author{
Please cite this article as: \\ Malešević Perović, L. and Mihaljević Kosor, M, \\ 2020. The Efficiency of Universities in Achieving \\ Sustainable Development Goals. Amfiteatru \\ Economic, 22(54), pp. 516-532.
}

\section{Article History}

Received: 23 December 2019

Revised: 4 February 2020

Accepted: 31 March 2020

DOI: $10.24818 / \mathrm{EA} / 2020 / 54 / 516$

\begin{abstract}
This paper investigates the efficiency of European universities in achieving Sustainable Development Goals (SDGs). We make use of newly published University Impact Rankings that account for SDGs, whereby institutions that achieved high scores are those that are, in addition to scientific research, putting more efforts in areas such as gender inequality, quality education for all, climate change, achieving peaceful societies and economic growth. In our empirical analysis, we adopt a dual approach. At a country level, we investigate efficiency of public expenditure on tertiary education, while at a university level we analyse the efficiency of the resources employed in achieving higher rankings (in terms of SDGs). Data Envelopment Analysis (DEA) results indicate that, at a macro level, only three to four countries in our sample are fully efficient. They could, therefore, without changing government tertiary expenditures on education, produce about $20 \%$ better score on University impact rankings. At a micro level, only about 16 percent of universities is efficient. Their performance could be much improved, without increasing the inputs, especially in terms of supporting SDGs through cooperation with other countries, the promotion of best practices and the publication of data in cooperation with foreign authors.
\end{abstract}

Keywords: Sustainable Development Goals (SDGs), European universities, Data Envelopment Analysis (DEA), government expenditures, efficiency

JEL Classification: Q01; I2; C14; H52

\section{Introduction}

* Corresponding author, Lena Malešević Perović - lena@efst.hr 
Modern economies are being progressively more based on knowledge and information, since knowledge, and consequently human capital, are recognised as key drivers of productivity, growth and prosperity of these countries. The necessity of investing in knowledge has already been recognised by many governments; moreover, the European Commission's 2020 strategy (European Commission, 2010) has put forward EU targets in the following five areas: employment, research and innovation, climate change and energy, education and poverty reduction. As noted by Gregersen et al. (2016), this strategy has been identified as the main path for Sustainable Development Goals (SDGs) implementation within Europe.

The United Nations' Transforming Our World: The 2030 Agenda for Sustainable Development, adopted in 2015 , is a global agreement committed to eliminating poverty and achieving sustainable development around the globe by year 2030. It contains 17 SDGs and 169 targets. Governments, businesses, various organizations and civil society should work together with the United Nations in order to achieve the Agenda by target year. Since education and research are explicitly recognised in a number of the SDGs, universities should get actively involved in addressing these goals. Moreover, the role of universities in achieving SDGs is much larger, as they can support their implementation and initiate change and social prosperity through study programs, curricula and research, as well as via adapting strategies and policies so that they reflect SDGs. The role of universities in supporting sustainable development is, thus, vital for the society as a whole, as its students represent a mechanism through which the transformation of the society towards sustainable development becomes possible. According to UNESCO (2017), a number of students in higher education (HE) in 2014 was about 207 million, and is expected to reach 380 million in 2030 (International Consultants for Education and Fairs (ICEF) Monitor, 2019). Universities, therefore, currently directly influence almost $3 \%$ of the world population, and as such should use their unique position within society, and play a critical role in the achievement of the SDGs.

Fiscal policies, on the other hand, are becoming more and more restrictive, as a response to financial crisis of 2007/08 as well as to growing government sectors around the world. Many countries in the world, European countries included, finance their higher education systems from public funds. According to Eurostat, government expenditures on tertiary education in the EU28 in 2015 was equivalent to $1.23 \%$ of GDP, and accounted for more than $25 \%$ of overall government expenditures on education. This type of spending, therefore, represents a significant portion of overall spending on education; hence, increased scrutiny is required to monitor the efficiency of its allocation. As noted by Mihaljević Kosor et al. (2019), many EU countries are expressing a growing sentiment that the existing HE systems are inefficient.

Having said all of the above, we set out to investigate efficiency in achieving sustainability (in terms of SDGs) of universities in a number of European countries. We adopt a dual approach in addressing this issue. From a macroeconomic perspective, we investigate the efficiency of public expenditure on tertiary education in achieving SDGs (given the number of teachers per capita) at a country level, while from a microeconomic perspective we analyse the efficiency in terms of achieving SDGs given the resources employed (number of students per staff, percentage of international students and number of FTE students) at a university level. To do so we apply Data Envelopment Analysis (DEA). DEA is a nonparametric method of mathematical programming, which assigns a set of weights to 
selected inputs and outputs. As such, it can be suitable method for both: country-level and university-level efficiency evaluation.

We use a newly published data, announced in 2019 - Times Higher Education University Impact Rankings, which represents the first global attempt to document evidence of universities' social, environmental and partnership impact on society. In addition to performance in teaching, research, knowledge transfer and international outlook typically accounted for in World University Rankings ${ }^{\dagger}$, these new rankings also account for 11 out of 17 above-mentioned SDGs. More precisely, these new scores reflect the success of universities in addressing sustainable development issues, such as gender inequality, quality education, climate change, achieving peaceful societies and economic growth, along with its research metrics. Overall, the better a university is in achieving SDGs, the higher the score on this list. On the other hand, since universities are mostly financed by governments, expenditures on tertiary education put financial pressures on government budgets. The main aim of this research is, thus, to assess the efficiency of universities in using these limited funds in achieving sustainability (in terms of SDGs), which translates into better scores on University Impact Rankings. The value-added of our approach lies in the fact that the efficiency of universities is typically not assessed with regard to sustainability. Rather, it is typically evaluated in terms of student attainment, enrolment rates, PISA scores etc. Our results suggest that without changing government tertiary expenditures on education, countries in the sample could, on average, produce about $20 \%$ better scores on University impact rankings. Therefore, it is not necessary to increase funding in order to achieve higher level of sustainability; on the contrary, better sustainability score could be achieved by keeping the same level of inputs and increasing efficiency.

The contributions of this paper lie in the fact that we use a newly published, idiosyncratic database, which contains university-level data on SDGs. In addition, our approach is novel as we combine this data with various educational inputs thus gaining insights into the efficiency of countries and universities in achieving SDGs. This approach has not been used before, to the best of knowledge. This paper further contributes to the literature by assessing this efficiency at two different levels: country- and university-level, thus addressing the same issue thoroughly - from macro- and micro-perspective.

This paper is organised as follows. Section 1 reviews scientific literature dealing with efficiency in education; Section 2 explains research methodology presenting the new database and the adopted empirical approach (DEA), while Section 3 discusses the Results. Conclusions are given in the final section

\section{Review of the scientific literature}

The past two decades have seen a rise in scholarly articles dealing with sustainable development and the role of higher education within it. A recent literature review of peerreviewed journal articles published between 2005 and 2017 by Findler et al. (2019) found 113 articles investigating the effects of HEIs on its stakeholders, economy, society and natural environment. The authors emphasized that higher education institutions have an inherent obligation to make societies more sustainable and higher education plays an important role in the global effort to achieve SDGs. Investigating the efficiency of HEIs in achieving these goals is, however a new area of study.

${ }^{\dagger}$ Also published by Times Higher Education 
The majority of studies on efficiency in HE have focused mostly on specific countries and their higher education institutions (HEIs) as the main decision making units (DMUs). The UK has a particularly long tradition in the efficiency analysis of HE. An early study using DEA for measuring and comparing the efficiency of UK's universities can be found in Athanassopoulos and Shale (1997). Using the data for 45 'old' universities in 1992-93 they find high technical efficiency in a model where inputs were student and staff numbers, quality of the student intake (mean A-level entry score) and financial variables and where outputs include number of successful leavers, number of degrees awarded and a research rating. Johnes (2008) extends this analysis and examines the efficiency of over 100 universities in the UK from 1996/97 to 2004/05. This study also confirms high average level of efficiency for UK's universities. More recent studies for UK can be found in Johnes (2014), Johnes and Johnes (2016) and Johnes and Tone (2017).

Australian HE system and its HEIs have also been extensively studied (see in Abbott and Doucouliagos, 2003; Avkiran 2001; Worthington and Lee, 2008). Other country specific studies on efficiency in HE can be found for Italy (Abramo et al. 2008; Agasisti and Dal Bianco, 2006; Ferrari and Laureti 2005), Germany (Fandel, 2007; Kempkes and Pohl, 2010), Greece (in Thanassoulis et al. 2017) and more recently for Spain (in Salas-Velasco, 2020).

Only a small number of studies measures HEI efficiency for several European countries. This is comprehensible given the problem of obtaining micro data on HE that can then be used for country comparison. Some of the examples are Joumady and Ris (2005) for 209 HEIs in eight European countries, Bonaccorsi, Daraio and Simar (2007) for six European countries (Italy, Norway, Portugal, Spain, Switzerland and the United Kingdom), Agasisti and Johnes (2009) for Italy and England, Wolszczak-Derlacz and Parteka (2011) for seven European countries (Austria, Finland, Germany, Italy, Poland, Switzerland and the United Kingdom), Agasisti and Wolszczak-Derlacz (2016) for Italy and Poland and Veiderpass and McKelvey (2016) for 17 European countries. We turn next to these three more recent studies.

Wolszczak-Derlacz and Parteka (2011) use a sample of 259 public HEIs from seven countries from 2001-2005. They find a relatively low level of efficiency of the HEIs in the sample i.e. the output could be improved by almost $55 \%$ by keeping the inputs stable over the time period of analysis. Their results also indicate that efficiency varies considerably within and between countries. Furthermore, they find that a higher share of funds from external sources and higher number of women in academic staff improve the efficiency of the HEI. Agasisti and Wolszczak-Derlacz (2016) evaluate the relative efficiency for 54 Italian and 30 Polish public universities in the period from 2001-2011. The inputs they use are related to the number of academic staff and total expenditures while the outputs vary depending on the model specification (number of students, graduates, publications and PhDs awarded). They find evidence that the efficiency is determined by the structure of university's revenues and academic staff. The authors found that over time the efficiency frontier improved more in Italy than in Poland. The research by Veiderpass and McKelvey (2016) includes observations on 944 HEIs in 17 European countries; however, these are only for the year 2008. Using DEA and a four-input, five-output model, the authors find that the provision of education is most efficient in the Slovak Republic, followed by Belgium and Latvia, while the lowest efficiency is found in Denmark and Norway. A 
positive relationship is also found between efficiency and HEI size and efficiency and research intensity.

On a macro, i.e. country level, several studies examine the efficiency of education in terms of government expenditures. As noted previously, universities should strive for maximum efficiency in allocating (limited) (government) resources while achieving educational outcomes. In DEA terms this means that government expenditures on tertiary education (\% GDP) are used as an input and various educational outcomes as outputs. Papers on the topic have used the following educational outcomes: HE enrolment rates (Obadić and Aristovnik, 2011); rate of labour force with HE (Obadić and Aristovnik, 2011); the unemployed with tertiary education (Obadić and Aristovnik, 2011; Ahec Šonje et al., 2018; Yotova and Stefanova, 2017; Toth, 2009); graduates in HE (Mihaljević Kosor et al., 2019); employment rates (Mihaljević Kosor et al., 2019); PISA scores (Gavurova et al. 2017; Sopek, 2011); tertiary educational attainment (Yotova and Stefanova, 2017); mean monthly earnings of person with tertiary education (Yotova and Stefanova, 2017), ratio of people with a degree to the total population (Toth, 2009) and World University Rankings (Ahec Šonje et al., 2018; Nadoveza Jelić and Gardijan Kedžo, 2018).

As can be seen, in both university - and country-level analyses, a variety of educational outcomes has been used. However, in this paper, we adopt a novel approach and observe the impact of selected inputs on University Impact Rankings that account for SDGs. Papers have not insofar investigated this aspect. Admittedly, Ahec Šonje et al. (2018) have used World University Rankings as a robustness check in their analysis of the efficiency of public expenditures on education in Croatia and other New Member States. They find that, for example, Croatia could decrease its input by 7.3 percentage points to keep its ranking unchanged. Similarly, Nadoveza Jelić and Gardijan Kedžo (2018) also use World University Rankings as an output indicator in one of the observed periods. To the best of our knowledge, no other papers have used similar variable in their research. We add to this strand of literature by using new rankings that also account for SDGs. In this context, we approximate the quality of tertiary education through university ranking scores, and observe their efficiency in achieving sustainability.

\section{Research methodology}

Times Higher Education University Impact Rankings

In 2019, Times Higher Education published the first edition of a new global University Impact Ranking that aims to measure institutions' success in delivering the SDGs. In addition to typically used performance indicators that measure institution's performance in teaching, research, knowledge transfers and international cooperation, this new edition also includes metrics based on the 11 SDGs that are the most relevant to Universities. These SDGs are as follows: SDG 3 - Good health and well-being; SDG 4 - Quality education; SDG 5 - Gender equality; SDG 8 - Decent work and economic growth; SDG 9 - Industry, innovation, and infrastructure; SDG 10 - Reduced inequalities; SDG 11 - Sustainable cities and communities; SDG 12 - Responsible consumption and production; SDG 13 - Climate action; SDG 16 - Peace, justice and strong institutions and SDG 17 - Partnerships for the goals.

Overall, 450 Universities from 76 countries are included in this edition. The data used refer to the closest academic year from January to December 2017. In this paper we will use two 
indicators from this database - university's overall score, and its score in SDG17 (since this is the only compulsory SDG for every university). A university's overall score is calculated by combining its score in SDG17 with its top three scores out of the remaining 10 SDGs. SDG17 accounts for $22 \%$ of the overall score, while the other SDGs account for $26 \%$ each. In this way, different universities are scored based on a different set of SDGs, depending on their focus. SDG17 - Partnership for the goals - assesses the ways in which universities support SDGs through cooperation with other countries, the promotion of best practices and the publication of data (Times Higher Education, 2019). Research metrics are provided by Elsevier while the data on SDGs are provided by universities themselves. For more details on methodology for calculating these scores, please see Times Higher Education (2019).

\section{Data and methodology}

The efficiency of a decision making unit (DMU) is defined as the ratio between the output(s) produced by the unit and the amount of resources used. An organisation is considered efficient if it produces a maximum amount of output(s) given the input(s) or, conversely, if it produces a fixed amount of output(s) using a minimum amount of input(s). The methodology applied in this paper is Data Envelopment Analysis (DEA), a renowned linear programming method for measuring relative efficiencies of DMUs, such as countries, banks, firms, hospitals, universities etc. The usage of DEA as an empirical tool for estimating the relative efficiency of education at various levels, be it country-level or secondary-, tertiary-, or some other level, has been very popular in recent years. The initial method for measuring technical efficiency against an efficiency frontier was first proposed by Farrell (1957) and the DEA method used in this paper can be considered as an extension of Farell's original methodology. A detailed examination of theoretical foundations of efficiency can be found in Charnes et al. (1993), and Färe et al. (1994) and it will not be presented here in breadth.

The HE system has some distinctive characteristics when compared to other levels of education. The contemporary higher education institutions are diverse, use multiple inputs to produce a range of outputs and carry out a number of activities extending further than teaching and research work. Additionally, most educational outcomes are not sold at market prices, thus making it difficult to attach a market value to those outcomes. DEA is, therefore, in this context an appealing choice as it can accommodate multiple inputs and outputs, while requiring no assumptions on the functional form linking inputs to outputs. This is particularly useful for public sector analysis, and more specifically education, where in the absence of market prices, the relationships cannot be explicitly specified. Lastly, DEA also offers a wealth of information for policy recommendations. It may inform us on the amounts the outputs/inputs could be increased/reduced, on benchmark DMUs that can potentially serve as role models for less efficient DMUs, etc.

Efficiency, as evaluated in this research, is a relative measure. Traditionally, it is in the range from 0 to 100 . We estimate the efficiency by which universities use their inputs in achieving SDGs. For the empirical analysis, we specify output-oriented, variable returns to scale model that is common in the efficiency of education literature. The output-orientation of the model implies that that the technology of the production process is directed at maximising output given the level of inputs. Individual efficiency scores are then calculated and compared for all corresponding DMUs. 
Since there is no consensus regarding the inputs and outputs that should be included in the analysis of education efficiency, the selection of which variables to include should be based on prior empirical works and peer judgement, so in our empirical analysis we adopt the following approach. In the first (macroeconomic) part of our analysis, we use two inputs and one output for each country. The inputs used are the government expenditures on tertiary education as a percentage of GDP (obtained from Eurostat), and the number of teachers in tertiary education per capita (obtained from UNESCO Institute for Statistics). The data is averaged for the period 2013-2017*. For output variable we use the overall score in University Impact Rankings and the score in achieving SDG17, in turn, which serve as a proxy for the quality of tertiary education (both variables were explained in more detail earlier). The number of universities that provided the data for each country varies (from one in Austria to 22 in United Kingdom). The approach we adopt, therefore, is to average the score over all universities for each country (average overall/SDG17 score). This occasionally resulted in a distorted country-level score, since one "bad" university in combination with several "good" universities could diminish the results for the country as a whole. Another approach is to use only the best-ranked university for each county (highest overall/SDG17 score). We use this as a robustness check.

In the second (microeconomic) part of our analysis, we use three inputs and one output for each country. The inputs used are number of students per staff, percentage of international students and number of full-time equivalent (FTE) students. The output, as before, is the overall score in University Impact Rankings and the score in achieving SDG17 (in turn), albeit this time they are calculated at a university level. Variable returns to scale are used throughout the analysis.

Countries included in the analysis comprise of 25 European countries: Austria, Bulgaria, Cyprus, Czech Republic, Denmark, Finland, France, Germany, Greece, Hungary, Iceland, Ireland, Italy, Latvia, Netherlands, Norway, Poland, Portugal, Romania, Slovakia, Spain, Sweden, Switzerland, Turkey and United Kingdom. The idea was to include European countries obtainable from the database, so data availability dictated the composition of the sample. Summary statistics for country- and university-level data are given in (tables no. 1 and 2), respectively.

Table no. 1 Summary statistics for country-level analysis

\begin{tabular}{|l|c|c|c|c|c|}
\hline Variable & Obs & Mean & Std. Dev. & Min & Max \\
\hline Average overall score & 25 & 65.78 & 13.33 & 38.70 & 94.80 \\
\hline Average SDG17 score & 25 & 55.44 & 17.48 & 18.60 & 88.55 \\
\hline Highest overall score & 25 & 75.57 & 15.53 & 38.70 & 96.20 \\
\hline Highest SDG17 score & 25 & 71.22 & 19.79 & 18.60 & 97.00 \\
\hline Government tertiary expenditures (\%) & 25 & 1.24 & 0.47 & 0.65 & 2.31 \\
\hline Number of tertiary teachers per capita & 25 & 0.32 & 0.15 & 0.14 & 0.69 \\
\hline
\end{tabular}

* The data is missing only for Turkey for government expenditures, for which we take the latest available data - from year 2006, and Hungary for number of teachers, for which we take the latest available data - from year 2012. 
In (table no. 1), both maximum of average overall score (94.8) and maximum of average SDG17 (88.5) refer to Sweden, while the maximum of the highest overall score, as well as the highest SDG17 score, was achieved by University of Manchester, UK. Minimum scores refer to Cyprus. The government of Denmark spends the most funds on tertiary education $(2.3 \%)$, while this spending is the smallest in Bulgaria $(0.65 \%)$. As for the number of tertiary teachers per capita, maximum (0.69) refers to Austria, and minimum (0.14) to Romania.

It should be stressed that there are overall 171 universities in the 25 countries in our sample; however, due to data unavailability for some of the variables we had to shorten the sample of universities to 115 . The data to be used in micro part of our empirical analysis is summarised in (table no. 2).

Table no. 2 Summary statistics for university-level analysis

\begin{tabular}{|l|c|c|c|c|c|}
\hline Variable & Obs & Mean & Std. Dev. & Min & Max \\
\hline Number of students per staff & 115 & 20.68 & 12.98 & 5.70 & 98.00 \\
\hline Percentage of international students & 115 & 0.16 & 0.12 & 0.01 & 0.53 \\
\hline Number of FTE students & 115 & 21525.04 & 15201.00 & 776.00 & 69737.00 \\
\hline Overall score & 115 & 69.01 & 15.93 & 38.70 & 96.20 \\
\hline SDG17 score & 115 & 56.28 & 23.97 & 18.60 & 97.00 \\
\hline
\end{tabular}

The university with the most students per staff in our sample (98) is Semmelweis University from Hungary, while École polytechnique from France has the lowest number of students per staff (5.07). SOAS University of London from UK and TOBB University of Economics and Technology from Turkey are universities with the highest (0.53) and lowest (0.01) percentage of international students, respectively. Finally, Ankara University from Turkey and Sant'Anna School of Advanced Studies - Pisa from Italy have the largest (69737) and the smallest (776) number of FTE students, respectively.

Following the nature of our research question, to assess the efficiency of universities in achieving SDGs, we use the so-called output-oriented DEA model, by treating the inputs as exogenously fixed and attempting to estimate maximum output levels, i.e. scores in terms of SDGs. The results are provided in Section 3.

\section{Results and discussion}

Country-level results

At a country level, we first analyse the results with average overall score as the output variable (table no. 3). Countries/institutions with high overall scores are those that are putting more efforts in areas such as gender inequality, quality education for all, climate change, achieving peaceful societies and economic growth. The average technical efficiency of government tertiary expenditures (controlling for the number of teachers per capita) for countries in our sample was $80.01 \%$. This suggests that countries in the sample provided, on average, $19.99 \%$ less output than they would, had they been efficient. Therefore, without changing government tertiary expenditures on education, countries in the sample could, on average, produce about $20 \%$ better score on University impact rankings. Higher scores mean that universities are making positive steps towards the SDGs. As indicated before, the overall score consists of a score in SDG17 and scores in additional 
three SDGs that vary by universities. If, for example, an overall score of a university were a result of a score in SDG13, this would mean that this particular university contributes to climate action, either via low carbon energy use, the presence of a university-wide climate action plan, and/or working with local or national government to address climate change planning. If its overall score was less than $100 \%$, then this university, and correspondingly a country, could, using the same amount of government expenditures on tertiary education, increase its climate concerns, and consequently its score on university rankings. Four countries in our sample stand out as $100 \%$ efficient. These are Hungary, Ireland, Italy and Sweden. In these countries, government expenditures were used in such a way as to reach the highest quality of education in terms of SDGs (measured by University Impact Rankings). It should be emphasised, however, that DEA calculates relative and not absolute efficiency scores, so the results refer only to the countries/universities in the sample. The least efficient country in our sample was Cyprus $(43.32 \%)$. Since this is an output-oriented model, these inefficiencies, for Cyprus concretely, mean that the unused output amounts to $56.68 \%$, i.e. that the same overall score in terms of SDGs could be achieved by reducing inputs drastically. Seven countries have efficiency score higher than the average value (80.01), but were not involved in the group of efficient countries, and these are: Netherlands, United Kingdom, Romania, Germany, Portugal, Greece and Spain. Fourteen countries have efficiency score under the total average.

(Table no. 4) gives the results of technical efficiency when SDG17 score is used as an output variable. Now Bulgaria, Hungary, Ireland and Sweden are 100\% efficient. Cyprus, however, is in an even worse position now, with efficiency score of only $22.12 \%$. The average technical efficiency is now $71.03 \%$, which is significantly lower than in (table no. 3 ). This result is to be expected since SDG17 is specific, and government expenditures cannot be expected to affect particular sustainability goal $100 \%$ efficiently everywhere.

In general, SDG17 focuses on partnerships between governments, the private sector and civil society. As noted previously, this is the only compulsory sustainable development goal in the overall score. It takes account of three categories: research $(27 \%)$, relationships to support goals $(23 \%)$ and publication of SDG reports $(50 \%)$. Within the first category, it focuses on papers that have been co-authored by foreign authors and the number of publications that relate to other 10 SDGs. The second category captures relationships between universities and governments or non-governmental organisations (NGOs) that promote best practices and cross-sectoral dialogue that support SDGs. Finally, publication of SDG reports refers to publication of specific data on the performance of universities with respect to other 10 SDGs. As evidenced by our results in (table no. 4), most European countries are still lagging in achieving this goal, i.e. they are below the efficiency frontier. They could, with the same amount of government spending on tertiary education produce a better score in SDG17, by focusing on cooperation with other countries, the promotion of best practices and the publication of data in cooperation with foreign authors.

As mentioned previously, we also use only the best-ranked university for each country (instead of the country average) as a robustness check. In this case only Italy and United Kingdom are found to be $100 \%$ efficient. Overall, there seems to be a lot of room for improvement in majority of countries. These high inefficiencies are to be expected given that only small sample of all universities in a particular country is included in this database. Moreover, the achievement of SDGs is a relatively new goal, and countries, as well as universities, are only just starting to pay more attention to it. At this stage, however, our 
results suggest that much improvement is needed. We next set out to investigate (in)efficiencies at a university level.

Table 3. DEA results at country level (output=average overall score)

\begin{tabular}{|l|c|c|}
\hline DMU = Country & Rank & $\begin{array}{c}\text { Efficiency } \\
\text { score }\end{array}$ \\
\hline Austria & 18 & 74.93 \\
\hline Bulgaria & 24 & 65.33 \\
\hline Cyprus & 25 & 43.32 \\
\hline Czech Republic & 14 & 78.09 \\
\hline Denmark & 16 & 77.06 \\
\hline Finland & 17 & 75.24 \\
\hline France & 12 & 79.83 \\
\hline Germany & 8 & 85.72 \\
\hline Greece & 10 & 81.72 \\
\hline Hungary & 1 & 100.00 \\
\hline Iceland & 15 & 77.69 \\
\hline Ireland & 1 & 100.00 \\
\hline Italy & 1 & 100.00 \\
\hline Latvia & 13 & 78.14 \\
\hline Netherlands & 5 & 93.54 \\
\hline Norway & 19 & 71.78 \\
\hline Poland & 22 & 67.63 \\
\hline Portugal & 9 & 84.51 \\
\hline Romania & 7 & 88.55 \\
\hline Slovakia & 21 & 68.00 \\
\hline Spain & 11 & 80.12 \\
\hline Sweden & 1 & 100.00 \\
\hline Switzerland & 23 & 66.99 \\
\hline Turkey & 20 & 71.50 \\
\hline United Kingdom & 6 & 90.54 \\
\hline
\end{tabular}

University-level results

Table 4. DEA results at country level (output=average SDG17 score)

\begin{tabular}{|l|c|c|}
\hline DMU = Country & Rank & $\begin{array}{c}\text { Efficiency } \\
\text { score }\end{array}$ \\
\hline Austria & 14 & 67.80 \\
\hline Bulgaria & 4 & 100.00 \\
\hline Cyprus & 25 & 22.12 \\
\hline Czech Republic & 16 & 67.33 \\
\hline Denmark & 21 & 48.56 \\
\hline Finland & 15 & 67.35 \\
\hline France & 12 & 70.96 \\
\hline Germany & 11 & 71.16 \\
\hline Greece & 19 & 63.80 \\
\hline Hungary & 1 & 100.00 \\
\hline Iceland & 24 & 36.31 \\
\hline Ireland & 1 & 100.00 \\
\hline Italy & 10 & 78.07 \\
\hline Latvia & 8 & 83.26 \\
\hline Netherlands & 6 & 88.90 \\
\hline Norway & 7 & 85.26 \\
\hline Poland & 5 & 89.93 \\
\hline Portugal & 13 & 68.36 \\
\hline Romania & 17 & 65.60 \\
\hline Slovakia & 23 & 47.85 \\
\hline Spain & 18 & 65.06 \\
\hline Sweden & 1 & 100.00 \\
\hline Switzerland & 22 & 48.09 \\
\hline Turkey & 20 & 57.19 \\
\hline United Kingdom & 9 & 82.70 \\
\hline
\end{tabular}

Due to space preservation reasons we present only 20 universities with the highest and 20 with the lowest efficiency in achieving overall scores (table no. 5) and SDG17 scores (table no. 6). The results for all 115 universities are available upon request.

Table 4. DEA results at university level (output=overall score)

\begin{tabular}{|l|l|c|c|}
\hline DMU = University & Country & Rank & $\begin{array}{c}\text { Efficiency } \\
\text { score }\end{array}$ \\
\hline Top 20 universities & \multicolumn{3}{|l|}{} \\
\hline University of Helsinki & Finland & 1 & 100 \\
\hline IMT Atlantique & France & 1 & 100 \\
\hline Centrale Nantes & France & 1 & 100 \\
\hline École polytechnique & France & 1 & 100 \\
\hline
\end{tabular}




\begin{tabular}{|c|c|c|c|}
\hline DMU = University & Country & Rank & $\begin{array}{c}\text { Efficiency } \\
\text { score }\end{array}$ \\
\hline Reykjavík University & Iceland & 1 & 100 \\
\hline Sant'Anna School of Advanced Studies- Pisa & Italy & 1 & 100 \\
\hline University of Calabria & Italy & 1 & 100 \\
\hline University of Padua & Italy & 1 & 100 \\
\hline Pompeu Fabra University & Spain & 1 & 100 \\
\hline University of A Coruña & Spain & 1 & 100 \\
\hline KTH Royal Institute of Technology & Sweden & 1 & 100 \\
\hline University of Gothenburg & Sweden & 1 & 100 \\
\hline Izmir Institute of Technology & Turkey & 1 & 100 \\
\hline Koç University & Turkey & 1 & 100 \\
\hline $\begin{array}{llll}\text { TOBB University } & \text { of } & \text { Economics } & \text { and } \\
\text { Technology } & & & \\
\end{array}$ & Turkey & 1 & 100 \\
\hline Boğaziçi University & Turkey & 1 & 100 \\
\hline Yeditepe University & Turkey & 1 & 100 \\
\hline SOAS University of London & United Kingdom & 1 & 100 \\
\hline University of Manchester & United Kingdom & 1 & 100 \\
\hline King's College London & United Kingdom & 20 & 99.63 \\
\hline \multicolumn{4}{|l|}{ Bottom 20 universities } \\
\hline The Open University & United Kingdom & 96 & 63.24 \\
\hline $\begin{array}{l}\text { National and Kapodistrian University of } \\
\text { Athens }\end{array}$ & Greece & 97 & 62.82 \\
\hline University of Warsaw & Poland & 97 & 62.82 \\
\hline University Rey Juan Carlos & Spain & 99 & 62.62 \\
\hline Technical University of Madrid & Spain & 100 & 62.21 \\
\hline Montpellier University & France & 101 & 62.15 \\
\hline Panthéon-Sorbonne University- Paris 1 & France & 102 & 61.97 \\
\hline $\begin{array}{l}\text { University of Chemistry and Technology } \\
\text { Prague }\end{array}$ & Czech Republic & 103 & 61.93 \\
\hline Sofia University & Bulgaria & 104 & 56.65 \\
\hline University of Oviedo & Spain & 105 & 54.69 \\
\hline University of Neuchâtel & Switzerland & 106 & 54.43 \\
\hline Technical University of Košice & Slovakia & 107 & 54.36 \\
\hline $\begin{array}{l}\text { Lappeenranta-Lahti University of Technology } \\
\text { LUT }\end{array}$ & Finland & 108 & 52.60 \\
\hline Cukurova University & Turkey & 109 & 52.11 \\
\hline Athens University of Economics and Business & Greece & 110 & 50.56 \\
\hline University of Jyväskylä & Finland & 111 & 50.49 \\
\hline $\begin{array}{l}\text { National institute of Applied Sciences of } \\
\text { Lyon (INSA Lyon) }\end{array}$ & France & 112 & 48.56 \\
\hline VSB- Technical University of Ostrava & Czech Republic & 113 & 43.15 \\
\hline Marmara University & Turkey & 114 & 41.97 \\
\hline Bahcesehir University & Turkey & 115 & 41.88 \\
\hline
\end{tabular}


The results (table no. 5) indicate that 19 universities are $100 \%$ efficient, while the average technical efficiency for all universities in our sample was $80.41 \%$. This means that 96 universities are operating beneath the efficiency frontier, and hence have the capacity to improve their performance. More precisely, universities in the sample could, on average, produce $19.6 \%$ better score on University impact rankings, using the same amount of inputs (number of students per staff, number of international students, and number of FTE students). 38 universities have efficiency scores higher than the average value, but were not involved in the group of efficient ones, while 58 have below-average efficiency scores. These universities could, using the same amount of inputs (number of students per staff, number of international students, and number of FTE students), achieve a better score in University Impact Rankings. King's College London could, for example, achieve $0.37 \%$ better score, while Bahçeşehir University could upgrade its efficiency by $58.12 \%$. For example, The Open University from United Kingdom, which achieved a score of 63.24, provided the data on SDG3, SDG4 and SDG10. It could, using the same amount of inputs increase its score in, say, SDG10 (Reduced inequalities) and consequently the overall score, by focusing on research that is relevant to reduced inequalities, motivating enrolment of first-generation students and students from low- and middle- income countries, increasing the proportion of students and staff with disabilities and applying more measures against discrimination.

Table 5. DEA results at university level (output=SDG17 score)

\begin{tabular}{|c|c|c|c|}
\hline DMU = University & Country & Rank & $\begin{array}{l}\text { Efficiency } \\
\text { score }\end{array}$ \\
\hline \multicolumn{4}{|l|}{ Top 20 universities } \\
\hline Sofia University & Bulgaria & 1 & 100 \\
\hline Aalto University & Finland & 1 & 100 \\
\hline University of Helsinki & Finland & 1 & 100 \\
\hline Centrale Nantes & France & 1 & 100 \\
\hline École polytechnique & France & 1 & 100 \\
\hline Reykjavík University & Iceland & 1 & 100 \\
\hline Sant'Anna School of Advanced Studies- Pisa & Italy & 1 & 100 \\
\hline University of Padua & Italy & 1 & 100 \\
\hline University of Latvia & Latvia & 1 & 100 \\
\hline Vrije Universiteit Amsterdam & Netherlands & 1 & 100 \\
\hline Pompeu Fabra University & Spain & 1 & 100 \\
\hline KTH Royal Institute of Technology & Sweden & 1 & 100 \\
\hline University of Gothenburg & Sweden & 1 & 100 \\
\hline Koç University & Turkey & 1 & 100 \\
\hline $\begin{array}{l}\text { TOBB University of Economics and } \\
\text { Technology }\end{array}$ & Turkey & 1 & 100 \\
\hline Brunel University London & United Kingdom & 1 & 100 \\
\hline King's College London & United Kingdom & 1 & 100 \\
\hline University of Manchester & United Kingdom & 1 & 100 \\
\hline Newcastle University & United Kingdom & 19 & 99.48 \\
\hline University of Bergen & Norway & 20 & 96.23 \\
\hline
\end{tabular}




\begin{tabular}{|l|l|c|c|}
\hline DMU = University & Country & Rank & $\begin{array}{c}\text { Efficiency } \\
\text { score }\end{array}$ \\
\hline $\begin{array}{l}\text { University of Chemistry and Technology } \\
\text { Prague }\end{array}$ & Czech Republic & 96 & 38.69 \\
\hline Sabanc1 University & Turkey & 97 & 38.16 \\
\hline University of Neuchâtel & Switzerland & 98 & 33.67 \\
\hline $\begin{array}{l}\text { Lappeenranta-Lahti University of Technology } \\
\text { LUT }\end{array}$ & Finland & 99 & 32.52 \\
\hline Technical University of Košice & Slovakia & 100 & 31.16 \\
\hline University of Oviedo & Spain & 101 & 30.25 \\
\hline University of Jyväskylä & Finland & 102 & 28.47 \\
\hline University of Iceland & Iceland & 103 & 27.29 \\
\hline Grigore T. Popa University of Medicine and & & & \\
Pharmacy & Romania & 104 & 25.98 \\
\hline Cukurova University & Turkey & 105 & 25.23 \\
\hline University of Valladolid & Spain & 106 & 24.82 \\
\hline Miguel Hernández University of Elche & Spain & 107 & 24.74 \\
\hline ISCTE-University Institute of Lisbon & Portugal & 108 & 24.20 \\
\hline Bangor University & United Kingdom & 109 & 22.60 \\
\hline University of Brescia & Italy & 110 & 22.51 \\
\hline Marmara University & Turkey & 111 & 20.75 \\
\hline Bahçeșehir University & Turkey & 112 & 20.06 \\
\hline Unversity of Pavia & Italy & 113 & 19.66 \\
\hline National and Kapodistrian University of Athens & Greece & 114 & 19.62 \\
\hline University Rey Juan Carlos & Spain & 115 & 19.60 \\
\hline
\end{tabular}

The results in (table no. 6) indicate that 18 universities achieved $100 \%$ efficiency in SDG17. On the other hand, there are three universities whose score is less than $20 \%$. Expectedly, when a specific SDG is accounted for, the results get worse, as it is unlikely that they would all be efficient in achieving these specific goals. For example, University of Bergen, from Norway, could, using the same number of students per staff, number of international students, and number of FTE students increase its SDG17 score by 3.77\%, by increasing the proportion of academic publications with co-authors from other countries and/or number of publications that relate to the 11 SDGs; by working on policy development with government or NGOs; promoting cross-sectoral dialogue with government or NGOs; collaborating internationally to capture data relating to SDGs; working internationally to promote best practice around SDGs, supporting the education of NGOs with respect to the SDGs and/or by publishing specific data on its performance against each of the remaining 10 SDGs. As evidenced by our results in (table no. 6), European universities are still lagging in achieving SDG17, i.e. they are below the efficiency frontier.

Sensitivity analysis was undertaken in two directions; by changing the used output variables (tables no. 4 and no. 6) and by excluding extreme observations and calculating correlation coefficients between the two estimations (results unreported but available upon request). The sensitivity analysis confirmed the robustness of our results. 


\section{Conclusions}

The main goal of this paper is to investigate efficiency of European universities in achieving Sustainable Development Goals. We make use of newly published University impact rankings that account for SDGs, and adopt a dual approach. At a country level, we investigate whether universities are efficient in using publicly provided funds for achieving SDGs, while at a university level we analyse the efficiency in achieving SDGs given the internal resources, in terms of staff and student numbers.

For our empirical analysis, we use DEA, a non-parametric method, which allocates weights to selected inputs and outputs, while assuming no functional form linking these two. At a country level only three to four (depending on the output variable) out of 25 countries in our sample are found to be fully efficient in achieving SDGs. Other countries are lagging behind, and several are extremely below the efficiency frontier. This suggests that government expenditures on tertiary education could be put into much better use, as they are currently used inefficiently. Our results, furthermore, indicate that only a small fraction of universities is efficient in achieving SDGs in general, and SDG17 in particular. Majority of 115 universities in our sample have below average efficiency scores. This finding suggests that university resources measured by the number of students per staff, number of international and number of FTE students are not used efficiently to achieve better university rankings in terms of SDGs. Their performance could be much improved, especially in terms of supporting SDGs through cooperation with other countries, the promotion of best practices and the publication of data in cooperation with foreign authors.

Overall, our results suggest that both countries and universities have the capacities to improve their performance. This means that without changing the inputs, they could enhance their performance in areas such as gender inequality, quality education for all, climate change, achieving peaceful societies and economic growth. These are the new global challenges that countries, as well as universities, should embrace and learn to incorporate in everyday activities. Sustainable development can be defined in various ways, but in general, it is an approach to development that accounts for environmental, social and economic sustainability which are not mutually exclusive. Indeed, there are more and more arguments recently that sustainable development, i.e. economic growth together with environmental protection, with the two reinforcing each other, should be the primary macroeconomic goal instead of pure GDP growth. Sustainable development 2030 Agenda, adopted by the UN in 2015, is a blueprint to achieve a better and more sustainable future for all and its 17 goals (SDGs) address key global challenges the world is faced with today. Better efficiency in achieving these goals from both, country and university level, is therefore crucial from the aspect of modern world policy makes, but also society as a whole.

The results should however be interpreted with caution. As briefly indicated above, the main problem in using DEA is that it allows for the comparison of relative efficiency between universities and does not examine absolute efficiency. Having a high score may sometimes just imply that those institutions are performing not quite so badly as the others in the sample. Additional critique in the efficiency measurement may be related to the lack of data on the quality of inputs and outputs. This is a general concern in this type of analysis.

Admittedly, a drawback of our research refers to the fact that universities provide their own data, and their participation is voluntary, so many world universities are not included in this list at all. This under-representation of some universities may lead to problems in 
generalizing our results. One of potential extensions of our research, therefore, would be the inclusion of more universities in the future, as the data becomes available, which would enable direct comparisons with World University Rankings. Additionally, each of the remaining 10 SDGs provided by the Times Higher Education database could be analysed separately and efficiency in achieving them assessed. Another venue for the extension of our paper includes investigating efficiency in achieving SDGs over the years, which will become possible in years to come. Finally, it would be interesting to see whether there exists convergence in educational outcomes in terms of SDGs within European countries. Namely, Malešević Perović et al. (2016) find that there is convergence of education expenditures in EU15. In terms of DEA this means that inputs are converging. It would, therefore, be valuable to observe whether there exists convergence of outputs in terms of University Impact Rankings.

\section{References}

Abbott, M. and Doucouliagos, C., 2003. The efficiency of Australian universities: a data envelopment analysis. Economics of Education Review, 22(1), pp. 89-97.

Abramo, G., D'Angelo, C.A. and Pugini, F., 2008. The measurement of Italian universities' research productivity by means of non-parametric-bibliometric methodology. Scientometrics, 76(2), pp. 225-244.

Agasisti, T. and DalBianco, A., 2006. Data envelopment analysis to the Italian university system: theoretical issues and political implications. International Journal of Business Performance, 8(4), pp. 344-367.

Agasisti, T. and Johnes, G., 2009. Beyond Frontiers: Comparing the Efficiency of Higher Education Decision-Making Units across More than One Country. Education Economics, 17(1), pp. 59-79.

Agasisti, T. and Wolszczak-Derlacz, J., 2016. Exploring efficiency differentials between Italian and Polish universities, 2001-11, Science and Public Policy, 43(1), pp. 128-142.

Ahec Šonje, A., Deskar-Škrbić, M. and Šonje, V., 2018. Efficiency of public expenditure on education: comparing Croatia with other NMS. MPRA Paper, No. 85152.

Athanassopoulos, A.D. and Shale, E., 1997. Assessing the Comparative Efficiency of Higher Education Institutions in the UK by Means of Data Envelopment Analysis. Education Economics, 5(2), pp.117-134.

Avkiran, N.K., 2001. Investigating Technical and Scale Efficiencies of Australian Universities through Data Envelopment Analysis. Socio-Economic Planning Sciences, 35(1), pp. 57-80.

Bonaccorsi, A., Daraio, C. and Simar, L., 2007. Efficiency and productivity in European universities: exploring trade-offs in the strategic profile, Chap. 5. In Bonaccorsi, A. and Daraio, C. (Eds.). Universities and strategic knowledge creation: Specialization and performance in Europe, Cheltenham/Northampton, MA: Edward Elgar Publishing, pp. 144-206.

Charnes, A., Cooper, W., Lewin, A. and Seiford, L., (1993). Data Envelopment Analysis: Theory, Methodology and Applications, Kluwer, Boston.

European Commission 2010. Europe 2020 - A European strategy for smart, sustainable and inclusive growth. Communication from the Commission, European Commission, Brussels (http://ec.europa.eu/eu2020/pdf/COMPLET\%20EN\%20BARROSO\%20\%20\%20007\% 2 0-\%20Europe\%202020\%20-\%20EN\%20version.pdf).

Eurostat database, http://appsso.eurostat.ec.europa.eu/nui/submitViewTableAction.do, [accessed 17.11.2019]. 
Fandel, G., 2007., On the Performance of Universities in North Rhine-Westphalia, Germany: Government's Redistribution of Funds Judged Using DEA Efficiency Measures. European Journal of Operational Research, 176(1), pp. 521-533.

Farrell, M., 1957. The Measurement of Productive Efficiency. Journal of the Royal Statistical Society. Series A (General) 120, pp. 253-290

Färe, R., Grosskopf, S. and Lovell, K., (1994). Production Frontiers, Cambridge University Press, Cambridge.

Ferrari, G. and Laureti, T., 2005. Evaluating technical efficiency of human capital formation in the Italian university: Evidence from Florence. Statistical Methods and Applications, 14(2), pp. 243-270.

Findler, F., Schönherr, N., Lozano, R., Reider, D., and Martinuzzi, A., 2019. The impacts of higher education institutions on sustainable development: A review and conceptualization, International Journal of Sustainability in Higher Education, 20(1), pp. 23-38.

Flegg, T., Allen, D., Field, K. and Thurlow, T.W., 2004. Measuring the efficiency of British universities: A multi-period data envelopment analysis. Education Economics 12(3), pp. 231-249.

Gavurova, B., Kocisova, K., Belas, L., and Krajcik, V., 2017. Relative efficiency of government expenditure on secondary education. Journal of International Studies, 10(2), pp. 329-343.

Gregersen, C., Mackie, J. and Torres, C., 2016. Implementation of the 2030 Agenda in the European Union: Constructing an EU approach to Policy Coherence for Sustainable Development, European Centre for Development Policy Management Discussion Paper, No. 197.

International Consultants for Education and Fairs (ICEF) Monitor, 2019. Study projects dramatic growth for global higher education through 2040, available at https://monitor.icef.com/2018/10/study-projects-dramatic-growth-global-highereducation-2040/.

Johnes, G. and Tone, K., 2017. The efficiency of Higher Education Institutions in England revisited: Comparing alternative measures, Tertiary Education and Management, 23(3), pp. 191-205.

Johnes, G., and Johnes, J., 2016. Costs, efficiency, and economies of scale and scope in the English higher education sector. Oxford Review of Economic Policy, 32(4), pp. 596-614.

Johnes, J., 2008. Efficiency and productivity change in the English higher education sector from 1996/97 to 2004/05. The Manchester School, 76(6), pp. 653-674.

Johnes, J., 2014. Efficiency and Mergers in English Higher Education 1996/97 to 2008/9: Parametric and Non-Parametric Estimation of the Multi-Input Multi-Output Distance Function. The Manchester School 82, pp. 465-487.

Joumady, O. and Ris, C., 2005. Performance in European higher education: a nonparametric production frontier approach. Education Economics, 13(4), pp. 189-205.

Kempkes, G. and Pohl, C., 2010. The efficiency of German universities: Some evidence from nonparametric and parametric methods. Applied Economics, 42, pp. 2063-2079.

Malešević Perović, L., Golem, S. and Mihaljević Kosor, M., 2016. Convergence in government spending components in EU15: a spatial econometric perspective. Amfiteatru Economic, 18(42), pp. 240-254. 
Mihaljević Kosor, M., Malešević Perović, L. and Golem, S., 2019. Efficiency of public spending on higher education: A Data envelopment analysis for EU-28. Problems of education in the $21^{\text {st }}$ century, 77(3), pp. 396-409.

Nadoveza Jelić, O. and Gardijan Kedžo, M., 2018. Efficiency vs effectiveness: an analysis of tertiary education across Europe, Public Sector Economics, 42(4), pp. 381-414.

Obadić, A. and Aristovnik, A., 2011. Relative efficiency of higher education in Croatia and Slovenia: an international comparison. Amfiteatru economic, 13(30), pp. 362-376.

Salas-Velasco, M., 2020. Measuring and explaining the production efficiency of Spanish universities using a non-parametric approach and a bootstrapped-truncated regression. Scientometrics 122 , pp. 825-846.

Sarrico, C.S. and Dyson, R.G., 2000. Using data envelopment analysis for planning in UK universities - An institutional perspective. Journal of the Operational Research Society, 51, pp. 789-800.

Sopek, P., 2011. Efficiency of public expenditure on education in Croatia. Newsletter: an occasional publication of the Institute of Public Finance, 13(61), pp. 1-12.

Thanassoulis, E., Kumar, P., Petridis, K., Goniadis, I. and Georgiou, A., 2017. Evaluating higher education teaching performance using combined analytic hierarchy process and data envelopment analysis. Journal of the Operational Research Society, 68(4), pp 431-445.

Times higher education, 2019. Available at https://www.timeshighereducation.com/ rankings/impact/2019/overall\#!/page/0/length/25/sort_by/rank/sort_order/asc/cols/undef ined

Toth, R., 2009. Using DEA to Evaluate Efficiency of Higher Education. APSTRACT: Applied Studies in Agribusiness and Commerce, pp. 79-82.

UNESCO Institute for Statistics (UIS) database, http://data.uis.unesco.org, [accessed 11.10.2019].

UNESCO, 2017. Six ways to ensure higher education leaves no one behind, UNESCO policy paper, No. 30, available at https://unesdoc.unesco.org/ark:/48223/ pf0000247862

Veiderpass, A. and McKelvey, M., 2016. Evaluating the performance of higher education institutions in Europe: a nonparametric efficiency analysis of 944 institutions, Applied Economics, 48(16), pp. 1504-1514,

Wolszczak-Derlacz, J. and Parteka, A., 2011. Efficiency of European public higher education institutions: a two-stage multicountry approach. Scientometrics, 89(3), pp. 887-917.

Worthington, A.C. and Lee, B.L., 2008. Efficiency, technology and productivity change in Australian universities, 1998-2003. Economics of Education Review, 27(3), pp. 285-298.

Yotova, L. and Stefanova, K., 2017. Efficiency of Tertiary Education Expenditure in CEE Countries: Data Envelopment Analysis. Economic Alternatives Journal, 3, pp. 352-364. 